\title{
EVALUASI FUNGSI EKOLOGIS RUANG TERBUKA HIJAU (RTH) PERKOTAAN SEBAGAI AREAL RESAPAN DI KOTA PONTIANAK (STUDI KASUS: TAMAN ALUN KAPUAS) \\ Febby Ekamukti Andini ${ }^{1}$, Yulisa Fitrianingsih ${ }^{1}$, Agus Ruliyansyah ${ }^{2}$ \\ 1) Program Studi Teknik Lingkungan Fakultas Teknik Universitas Tanjungpura, Pontianak \\ ${ }^{2)}$ Program Studi Agroteknologi Fakultas Pertanian Universitas Tanjungpura, Pontianak Email : febbyandini52@yahoo.co.id
}

\begin{abstract}
ABSTRAK
Taman Alun Kapuas merupakan taman kota yang ditetapkan Dinas Pertamanan sebagai Ruang Terbuka Hujau (RTH) di Kota Pontianak. Terkait dengan fungsi RTH sebagai resapan air hujan, Taman Alun Kapuas kurang diperhatikan karena genangan sering terjadi pada musim penghujan. Penelitian ini bertujuan untuk mengetahui 1) laju infiltrasi saat kondisi hari tidak hujan dan kondisi hari hujan, 2) pengaruh karakteristik fisik tanah dan vegetasi terhadap laju infiltrasi, 3) potensi Taman Alun Kapuas dalam meresapkan air hujan. Pengukuran laju infiltrasi menggunakan double ring infiltrometer, kemudian dianalisis dengan metode Horton. Hasil penelitian menunjukkan laju infiltrasi rata-rata pada kondisi hari tidak hujan sebesar 5,62 cm/jam lebih besar dari kondisi hari hujan sebesar $3,20 \mathrm{~cm} / \mathrm{jam}$. Laju infiltrasi tertinggi pada Titik 4 sebesar 14,40 cm/jam mempunyai tanah pasir sebesar 64,64\%, permeabilitas $26,29 \mathrm{~cm} / \mathrm{jam}$, dan porositas 55,42\%. Laju infiltrasi terendah pada Titik 3 sebesar 2,02 m/jam mempunyai tanah pasir $54,41 \%$, permeabilitas 5,14 cm/jam, dan porositas $47,33 \%$. Semakin besar nilai permeabilitas, porositas, dan fraksi pasir, maka laju infiltrasi meningkat. Kondisi vegetasi pada Titik 1, Titik 2, dan Titik 4 didominasi dengan pohon dan rumput mempunyai laju infiltrasi lebih besar daripada Titik 3 yang didominasi tanaman ground cover dan perdu. Potensi peresapan air hujan dalam satu tahun di Taman Alun Kapuas 37\% dari volume total curah hujan sebesar $54.801 \mathrm{~m}^{3}$, sehingga belum memenuhi fungsi ekologis taman kota sebagai area resapan sebesar $75-95 \%$. Beberapa hal yang dapat disarankan adalah memperluas area penghijauan, komposisi vegetasi yang tepat untuk resapan, mengganti aspal dengan paving block, dan kegiatan sosial-ekonomi tidak dilakukan pada area penghijauan.
\end{abstract}

Kata kunci: taman kota, laju infiltrasi, karakteristik fisik tanah, vegetasi

\section{ABSTRACT}

Alun Kapuas Park is a city park that designated by The Park Departement as Green Open Space (RTH) in Pontianak city. In connection with the function of RTH as rainwater catchment, Alun Kapuas Park still got less attention because puddle often happens during the rainy season. This research aims to determine 1) infiltration rate when the condition is not raining and the day condition is raining, 2) the influence of soil physical characteristic and vegetation against the infiltration rate, 3) the potential of Alun Kapuas Park to absorb rainwater. Infiltration rate measurement method uses double ring infiltrometer, then it is analyzed by the method of Horton. The result of research indicate that the condition of dry day has average infiltration rate value of $5,62 \mathrm{~cm} / \mathrm{h}$ greater than the condition of rainy days has average infiltration rate value of 3,20 $\mathrm{cm} / \mathrm{h}$. The highest infiltration rate value of $14,40 \mathrm{~cm} / \mathrm{h}$ is point 4 with sand soil value of $64,64 \%$, permeability value of $26,29 \mathrm{~cm} / \mathrm{h}$, and porosity value of $55,42 \%$. Lowest infiltration rate value of $2,02 \mathrm{~cm} / \mathrm{h}$ is point 3 , with sand soil value of $54,41 \%$, permeability value of $5,14 \mathrm{~cm} / \mathrm{h}$, and porosity value of $47,33 \%$. The greater values of permeability, porosity, and the sand fraction can increase the infiltration rate. Vegetation at Point 1, Point 2 and Point 4 is dominated by trees and grass have infiltration rate greater than 3 points dominated the ground cover plants and shrubs. Potential seepage of rain for one year in Alun Kapuas Park is $37 \%$ of the total volume of rainfall amounted to $54.801 \mathrm{~m}^{3}$, so it does not fulfill the ecological functions of city park as rainwater catchment have percentage of $75-95 \%$. Something that can be suggested is expanding the area of reforestation, choosing the composition of the vegetation right, replacing asphalt with paving blocks, and social-economic activities are not carried out in the area of reforestation.

Key word: city park, infiltration rate, soil physical characteristic, vegetation 


\section{PENDAHULUAN}

Keberadaan ruang terbuka hijau merupakan salah satu unsur penting dalam membentuk lingkungan kota yang nyaman dan sehat. Taman kota merupakan salah satu lahan ruang terbuka hijau. Ketersediaan taman di Kota Pontianak belum memenuhi kategori sebagai taman berskala kota yang baik dari sisi luasan area hingga fasilitas dan vegetasi masih sangat kurang (Bappeda Kota Pontianak, 2012).

Taman Alun Kapuas merupakan taman kota yang ditetapkan Dinas Pertamanan sebagai Ruang Terbuka Hujau (RTH) di Kota Pontianak. Menurut Permen PU No.05 Tahun 2008, salah satu fungsi ekologis pada taman kota adalah penyerap air hujan. Taman kota dapat berperan dalam membantu penyerapan air agar pasokan air dalam tanah (water saving) semakin meningkat dan mereduksi potensi banjir dengan mengurangi jumlah aliran limpasan air. Namun, permasalahan genangan air sering terjadi pada permukaan jalan di Taman Alun Kapuas saat musim penghujan. Terkait dengan fungsi RTH sebagai resapan, Taman Alun Kapuas masih kurang diperhatikan dibandingkan dengan fungsi-fungsi RTH yang lain. Hal ini dapat dilihat dari luas penghijauan yang lebih kecil dibandingkan dengan perkerasan.

Tentunya permasalahan tersebut mengganggu kenyamanan masyarakat kota, serta menurunkan nilai ekonomi dan estetika dari Taman Alun Kapuas. Harapan dari penelitian ini, taman kota tidak hanya dianggap sebagai tempat rekreasi saja, tetapi juga bermanfaat sebagai areal resapan yang mampu mereduksi genangan. Oleh karena itu, pada penelitian ini akan mengkaji fungsi ekologis taman kota sebagai areal resapan agar dapat menjadi bahan evaluasi untuk mengatasi permasalahan genangan.

\section{METODOLOGI PENELITIAN}

\section{A. Lokasi Penelitian}

Penelitian ini dilakukan pada Taman Alun Kapuas yang terletak di Jalan Rahadi Usman Kecamatan Pontianak Kota. Pemilihan Taman Alun Kapuas sebagai lokasi penelitian karena tergolong dalam kawasan Ruang Terbuka Hijau (RTH) Perkotaan yang telah ditetapkan oleh Dinas Pertamanan dan Kebersihan Kota Pontianak dan terletak di pusat kota.

\section{B. Prosedur Penelitian}

$>$ Pengamatan Genangan

Pengamatan genangan dilakukan setelah terjadi kejadian hujan. Tujuannya adalah untuk mengetahui titik pengambilan tanah dan pengukuran laju infiltrasi berdasarkan kondisi area terjadi genangan. Pengambilan tanah dan pengukuran laju infiltrasi dilakukan pada 4 titik, yaitu Titik 1 dan Titik 2 merupakan area genangan, sedangkan Titik 3 dan Titik 4 merupakan area tidak terjadi genangan. Area tidak terjadi genangan dipilih agar dapat mengetahui penyebab terjadinya genangan berdasarkan karakteristik tanah dan laju infiltrasi. Titik pengambilan sampel tanah dan pengukuran laju infiltrasi di Taman Alun Kapuas adalah sebagai berikut. 


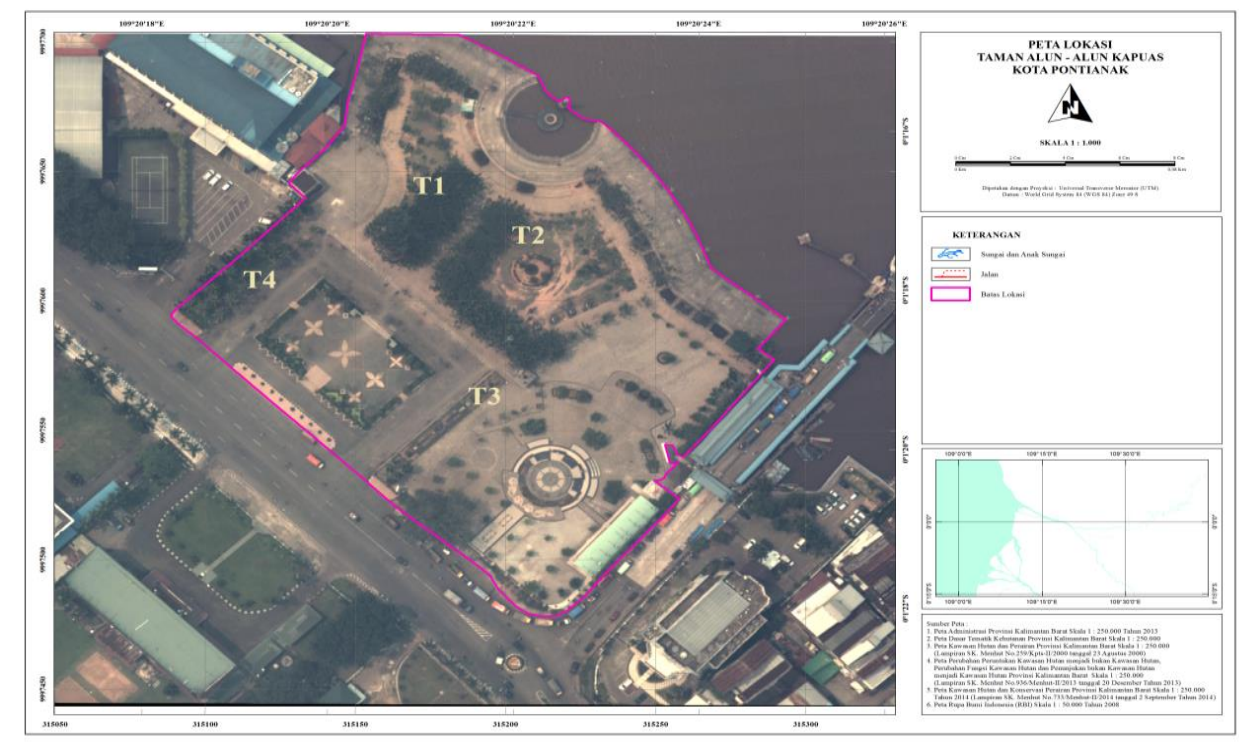

Gambar 1. Titik Pengambilan Sampel Tanah dan Pengukuran Laju Infiltrasi

\section{$>$ Pengambilan Sampel Tanah}

Pengambilan sampel tanah dilakukan satu kali pada masing-masing titik yang telah ditentukan. Sampel tanah digunakan untuk mengetahui tekstur tanah, porositas, permeabilitas dan kadar air tanah. Pengambilan sampel tanah menggunakan tabung silinder dari besi dengan diameter $5 \mathrm{~cm}$. Pertama-tama, tanah yang menjadi bahan untuk pengambilan contoh tanah dibersihkan dan diratakan permukaannya. Tabung silinder besi pada bagian ujung yang tajam diletakkan tegak pada tanah tersebut lalu ditekan ke dalam menggunakan bor tanah. Setelah tanah utuh diperoleh, tabung diangkat dan dibersihkan sisa-sisa tanah dengan menggunakan karter. Tanah dipotong sampai rata dan utuh di dalam tabung, kemudian ditutup dengan plastik agar kelembaban tanah terjaga. Selanjutnya menulis label tentang informasi lokasi dan kedalaman pengambilan contoh tanah pada tutup tabung, kemudian masukkan contoh tanah ke dalam peti.

\section{$>$ Pengukuran Laju Infiltrasi}

Laju infiltrasi diukur secara langsung di lapangan dengan menggunakan alat double ring infiltrometer. Pengukuran laju infiltrasi tanah akan dilakukan dua kali pada masing-masing titik pengukuran, yaitu pada kondisi tidak hujan dan kondisi hujan. Pengukuran akan diulangi satu kali pada kondisi yang sama agar diperoleh data yang lebih akurat. Adapun alat-alat yang diperlukan dalam pengukuran ini antara lain penggaris, air, ember, gayung, stopwatch, double ring infiltrometer dengan besar berdiameter $50 \mathrm{~cm}$ dan kecil berdiameter $30 \mathrm{~cm}$, alat tulis, kayu, alat pemukul, plastik, dan spons.

Infiltrometer dimasukkan ke dalam tanah dengan kedalaman sekitar antara 10 $\mathrm{cm}$ dengan menggunakan alat pemukul, dengan kedudukan diusahakan tegak lurus serta tanah dalam silinder dijaga jangan sampai rusak atau pecah. Pengisian air dilakukan secara perlahan-lahan pada silinder kecil agar tidak merusak struktur permukaan tanah. Pengamatan infiltrasi dilakukan dengan melihat besar penurunan air pada silinder bagian dalam melalui mistar yang sudah terpasang. Apabila ketinggian air pada silinder dalam sudah menurun sampai batas waktu tertentu, maka air harus segera ditambahkan ke dalamnya. Penambahan air terus 
dilakukan hingga skala penurunan air konstan. Pengukuran waktu pada saat terjadi penurunan ketinggian air dengan menggunakan stopwatch/alat pengukur waktu.

\section{Teknik Analisis Data}

$>$ Karakteristik fisik tanah

Analisis karakteristik fisik tanah dilakukan di laboratorium Ilmu Tanah Fakultas Pertanian Universitas Tanjung Pura. Analisis akan dilakukan satu kali pada masingmasing titik pengukuran. Adapun karakteristik fisik tanah yang akan dianalisis adalah tekstur tanah, porositas tanah, kadar air dan permeabilitas tanah.

Laju Infiltrasi

Pengolahan data dari hasil pengukuran infiltrometer menggunakan metode Horton. Model Horton dapat dinyatakan secara matematis adalah sebagai berikut.

$f=f c+(f o-f c) e^{-k t}$

Keterangan:

$f=$ laju infiltrasi nyata $(\mathrm{cm} / \mathrm{jam})$

$\mathrm{fc}=$ laju infiltrasi tetap $(\mathrm{cm} / \mathrm{jam})$

fo $=$ laju infiltrasi awal $(\mathrm{cm} / \mathrm{jam})$

$\mathrm{k}=$ konstanta geofisik

$\mathrm{t}=$ waktu

$>$ Koefisien Resapan

Koefisien resapan adalah banyaknya volume curah hujan yang mengalir sebagai air infiltrasi terhadap total curah hujan. Untuk mendapatkan angka koefisien resapan ( $R$ ) tahunan suatu daerah resapan, rumus yang digunakan adalah:

$R=\frac{I \times 365 \times A}{P \times A}$

Keterangan:

1 = laju infiltrasi ( $\mathrm{mm} /$ hari)

$P=$ rata-rata curah hujan tahunan selama 10 Tahun terakhir $(\mathrm{mm})$

$A=$ luas daerah berpotensi peresapan $\left(\mathrm{m}^{2}\right)$

Koefisien Resapan juga dapat diperoleh dengan persamaan: $R=1-C$ dimana nilai $C$ adalah koefisien limpasan. Semakin kecil koefisien limpasan maka koefisien resapan yang diperoleh semakin besar.

\section{$>$ Potensi Peresapan}

Potensi peresapan atau volume air hujan yang dapat diresapkan dalam 1 tahun, dihitung dengan perkalian curah hujan $(P)$ dengan luas daerah yang berpotensi peresapan (A) dan koefisien resapan (C). Menurut Asdak (2002), cara sederhana untuk perhitungan volume resapan dapat dilakukan dengan persamaan:

Volume Resapan $=\frac{P}{1000} \times A \times R=\frac{P}{1000} \times A \times(1-C)$

Keterangan:

$\mathrm{P}=$ rata-rata curah hujan tahunan selama 10 Tahun terakhir

$A=$ luas daerah berpotensi peresapan

$\mathrm{R}=$ koefisien resapan

$\mathrm{C}=$ koefisien limpasan 


\section{HASIL DAN ANALISA}

\section{A. Laju Infiltrasi pada Kondisi Tidak Hujan dan Kondisi Hujan}

Dilihat dari klasifikasi menurut Kohnke (1980), laju infiltrasi rata-rata saat tidak hujan sebesar 5,62 cm/jam dan laju infiltrasi rata-rata saat hujan sebesar $3,20 \mathrm{~cm} / \mathrm{jam}$ tergolong sedang. Hal ini menunjukkan Taman Alun Kapuas mempunyai potensi sebagai area resapan. Berdasarkan pada Tabel 1 dapat diketahui bahwa curah hujan dapat menurunkan laju infiltrasi tanah. Penurunan laju infiltrasi terjadi pada semua titik pengukuran. Hal ini dapat dilihat pula dari laju infiltrasi rata-rata saat hari hujan lebih kecil daripada saat hari tidak hujan.

Tabel 1. Laju Infiltrasi di Taman Alun Kapuas

\begin{tabular}{|c|c|c|c|c|c|}
\hline \multirow[t]{2}{*}{ Kondisi } & \multirow[t]{2}{*}{ Titik } & \multicolumn{2}{|c|}{$\begin{array}{c}\text { Laju Infiltrasi } \\
\text { (cm/jam) }\end{array}$} & \multirow{2}{*}{$\begin{array}{c}\text { Rerata Laju Infiltrasi } \\
\text { tiap Titik Pengukuran } \\
\text { (cm/jam) }\end{array}$} & \multirow{2}{*}{$\begin{array}{c}\text { Klasifikasi } \\
\text { Menurut Kohnke } \\
\text { (1980) }\end{array}$} \\
\hline & & 1 & 2 & & \\
\hline \multirow{4}{*}{$\begin{array}{l}\text { Hari } \\
\text { Tidak } \\
\text { Hujan }\end{array}$} & $\mathrm{T} 1$ & 1,86 & 2,39 & 2,13 & Sedang \\
\hline & $\mathrm{T} 2$ & 3,86 & 4,03 & 3,94 & Sedang \\
\hline & T3 & 2,15 & 1,89 & 2,02 & Sedang \\
\hline & T4 & 15,18 & 13,62 & 14,40 & Cepat \\
\hline \multicolumn{4}{|c|}{ Rerata Laju Infiltrasi } & 5,62 & Sedang \\
\hline \multirow{4}{*}{$\begin{array}{l}\text { Hari } \\
\text { Hujan }\end{array}$} & $\mathrm{T} 1$ & 0,77 & 1,90 & 1,34 & Sedang Lambat \\
\hline & $\mathrm{T} 2$ & 2,05 & 2,21 & 2,13 & Sedang \\
\hline & T3 & 0,57 & 0,56 & 0,57 & Sedang Lambat \\
\hline & $\mathrm{T} 4$ & 7,82 & 9,68 & 8,75 & Sedang Cepat \\
\hline \multicolumn{4}{|c|}{ Rerata Laju Infiltrasi } & 3,20 & Sedang \\
\hline
\end{tabular}

Sumber: Hasil Analisis, 2015

Menurut Sinukaban (2007), pada saat tanah kering laju infiltrasi tinggi, setelah tanah menjadi jenuh air maka laju infiltrasi akan menurun dan menjadi konstan. Pada waktu permulaan curah hujan, laju infiltrasi akan menurun seiring bertambahnya waktu. Jika hujan turun terus, air hujan yang mencapai permukaan tanah akan meresap ke dalam tanah (infiltrasi) sampai mencapai suatu taraf dimana intensitas hujan melebihi kapasitas infiltrasi tanah. Hal ini disebabkan karena tanah makin jenuh dan sebagian rongga tanah sudah terisi oleh butiran tanah berkembang.

Pendapat ini juga sejalan dengan Kurnia (2006) bahwa laju infiltrasi pada awalnya tinggi, dengan masuknya air lebih dalam dan lebih dalamnya profil tanah yang basah, maka hisapan matriks tanah berkurang dan akhirnya hanya tinggal tarikan gravitasi yang berpengaruh terhadap pergerakan air, menyebabkan laju infiltrasi semakin menurun dengan berjalannya waktu mendekati kondisi kesetimbangan (steady state). Oleh karena itu, laju infiltrasi yang dianggap paling efektif adalah kondisi saat tidak hujan karena tanah dalam kondisi kering memiliki daya serap yang tinggi.

\section{B. Pengaruh Karakteristik Fisik Tanah terhadap Laju Infiltrasi}

Keterkaitan sifat fisik tanah dan infiltrasi sangat besar karena keduanya saling mempengaruhi. Beberapa sifat fisik tanah yang dapat mempengaruhi laju infiltrasi yaitu tekstur tanah, porositas, kadar air, dan permebilitas tanah. Berdasarkan pada klasifikasi kelas tekstur tanah (Hiller, 1971), sampel tanah pada Titik 1, Titik 3, dan Titik 4 tergolong dalam tanah bertekstur lempung liat berpasir, sedangkan sampel tanah pada Titik 2 tergolong lempung berliat. Hasil yang diperoleh dari pengambilan sampel tanah pada masing-masing titik dapat dilihat pada Tabel $\mathbf{2}$ sebagai berikut. 
Tabel 2. Karakteristik Fisik Tanah

\begin{tabular}{|c|c|c|c|c|c|c|c|}
\hline \multirow{2}{*}{ Titik } & \multirow{2}{*}{$\begin{array}{l}\text { Permeabilitas } \\
\text { (cm/jam)* }\end{array}$} & \multirow{2}{*}{$\begin{array}{c}\text { Porositas } \\
(\%)^{*}\end{array}$} & \multirow{2}{*}{$\begin{array}{c}\text { Kadar } \\
\text { Air } \\
(\%)^{*}\end{array}$} & \multicolumn{3}{|c|}{ Tekstur Tanah (\%)** } & \multirow{2}{*}{ Jenis Tanah } \\
\hline & & & & Pasir & Debu & Liat & \\
\hline $\mathrm{T} 1$ & 8,26 & 50 & 32,72 & 54,68 & 13,65 & 31,67 & Lempung liat berpasir \\
\hline $\mathrm{T} 2$ & 10,95 & 40,79 & 30,86 & 44,39 & 24,20 & 31,41 & Lempung berliat \\
\hline T3 & 5,14 & 47,33 & 32,40 & 54,41 & 14,67 & 30,92 & Lempung liat berpasir \\
\hline T4 & 26,29 & 55,42 & 37,15 & 64,64 & 3,82 & 31,54 & Lempung liat berpasir \\
\hline
\end{tabular}

Sumber:* Laboratorium Fisika Tanah Fakultas Pertanian UNTAN, 2015

* Laboratorium Kimia Tanah Fakultas Pertanian UNTAN, 2015

Menurut Hammer (1981), permeabilitas dapat diklasifikasikan menjadi sedang $<<$ $0,5 \mathrm{~cm} / \mathrm{jam})$, lambat $(0,5-2 \mathrm{~cm} / \mathrm{jam})$, sedang lambat $(2-6,3 \mathrm{~cm} / \mathrm{jam})$, sedang $(6,3-$ $12,7 \mathrm{~cm} / \mathrm{jam})$, sedang cepat $(12,7-24,4 \mathrm{~cm} / \mathrm{jam})$, dan cepat $(>24,4 \mathrm{~cm} / \mathrm{jam})$. Berdasarkan pada Tabel 2 dapat dilihat nilai permeabilitas di Titik 1 dan Titik 2 tergolong sedang, Titik 3 tergolong sedang lambat, dan Titik 4 tergolong cepat.

Pada Tabel 2 menunjukkan bahwa Titik 3 mempunyai permeabilitas dan laju infiltrasi paling rendah yaitu $5,14 \mathrm{~cm} / \mathrm{jam}$ dan laju infiltrasi sebesar $2,02 \mathrm{~cm} / \mathrm{jam}$. Padahal apabila dilihat dari segi tekstur pada Titik 3 mempunyai komponen pasir sebesar $54,41 \%$ dengan porositas $47,33 \%$ lebih tinggi dari Titik 2 yang mempunyai komponen sebesar $44,39 \%$ dengan porositas $40,79 \%$. Hasil ini bertolak belakang dengan teori bahwa pada tekstur tanah pasir yang memiliki ruang pori besar, akan memiliki daya infiltrasi yang cepat dan permeabilitasnya sangat tinggi (Soepardi, 1975). Faktor yang dapat mempengaruhi nilai permeabilitas dan laju infiltrasi di Titik 3 adalah pada saat pengambilan sampel tanah dalam kondisi menyimpan air. Hal ini dapat dilihat pada Tabel 2 bahwa kadar air di Titik 3 sebesar 32,40\% lebih tinggi dari Titik 2 sebesar 30,86\%. Tingginya kadar air tanah akan diikuti laju infiltrasi yang lama karena kandungan air yang ada didalam tanah sudah tinggi (Wirosoedarmo, 2009). Oleh karena itu, nilai permeabilitas dan laju infiltrasi tanah di Titik 3 lebih kecil dibandingkan dengan titik pengukuran yang lain.

Berbeda dengan Titik 3, pada Titik 2 mempunyai nilai permeabilitas 10,95 cm/jam dan laju infiltrasi sebesar $3,94 \mathrm{~cm} / \mathrm{jam}$. Padahal apabila dilihat dari segi tekstur pada Titik 2 mempunyai komponen pasir sebesar 44,39\% dengan porositas 40,79\% lebih rendah dari Titik 3 yang mempunyai komponen sebesar $54,41 \%$ dengan porositas $40,79 \%$. Hal ini dapat dikarenakan pengambilan sampel tanah dan pengukuran laju infiltrasi dilakukan pada hari yang berbeda. Menurut Arsyad (1989), laju infiltrasi dapat terpelihara jika porositas semula tetap tidak terganggu selama waktu tidak terjadi hujan. Pada saat pengambilan sampel kemungkinan porositas tanah berubah karena mengalami pemadatan oleh curah hujan dan aktivitas manusia.

Laju infiltrasi terbesar berada pada Titik 4, yaitu $14,40 \mathrm{~cm} / \mathrm{jam}$ tergolong cepat. Dilihat dari tekstur tanah, Titik 4 mempunyai komponen pasir sebesar $64,64 \%$ dengan porositas tergolong baik yaitu sebesar 55,42\%. Menurut Arsyad (1989), porositas yang berada pada rentang $50-60 \%$ tergolong baik dan $40-50 \%$ tergolong kurang baik. Laju infiltrasi yang tinggi pada Titik 4 dikarenakan nilai permeabilitas yang tergolong cepat sebesar $26,29 \mathrm{~cm} / \mathrm{jam}$. Begitupula pada Titik 1 mempunyai nilai permeabilitas yang tergolong sedang sebesar $8,26 \mathrm{~cm} / \mathrm{jam}$ dan nilai porositas $50 \% \mathrm{Hal}$ ini sejalan dengan hasil penelitian Andayani (2009), laju infiltrasi berbanding lurus dengan porositas dan permeabilitas. Semakin tinggi porositas dan permeabilitas maka laju infiltrasinya makin tinggi. 


\section{Pengaruh Vegetasi terhadap Laju Infiltrasi}

Permukaan tanah yang tertutup vegetasi berupa pohon-pohon dan rumputrumputan akan mempercepat laju infiltrasi. Menurut Harto (1993), tanaman di atas permukaan tanah berpengaruh terhadap laju infiltrasi dengan dua cara, yaitu berfungsi menghambat aliran air di permukaan sehingga kesempatan berinfiltrasi lebih besar, dan sistem perakaran yang dapat lebih menggemburkan struktur tanahnya. makin baik tutupan tanaman yang ada, laju infiltrasi cenderung lebih tinggi.

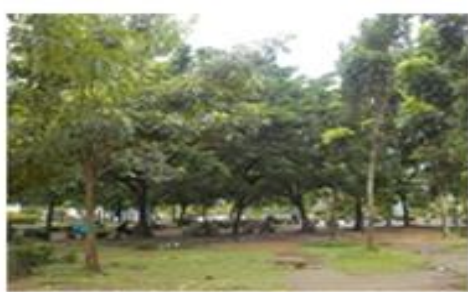

a) Titik 1

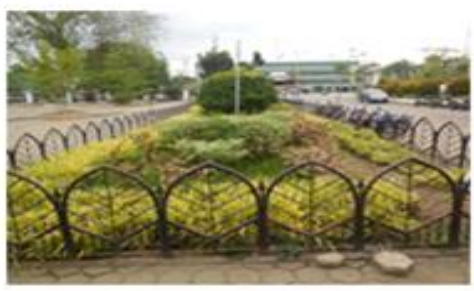

c) Titik 3

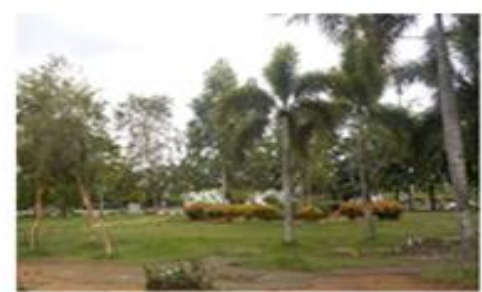

b) Titik 2

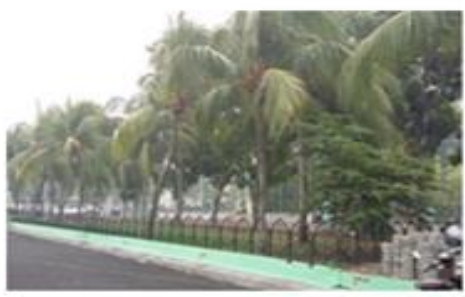

d) Titik 4

Gambar 2. Vegetasi di Taman Alun Kapuas

Berdasarkan hasil pengamatan, pada Titik 1 didominasi dengan vegetasi pohon berupa trembesi dan mahoni yang berfungsi untuk mengatasi genangan, serta sedikit rerumputan. Begitupula pada Titik 2 mempunyai vegetasi pohon, perdu, dan rerumputan. Pohon yang berperan dalam mengatasi penggenangan dan pelestarian air tanah antara lain akasia, trembesi, mahoni, dan bungur. Namun, Titik 1 dan Titik 2 merupakan area terjadi genangan. Hal ini tidak sesuai dengan pendapat Soeharto (2006) bahwa vegetasi tingkat pohon mempunyai fungsi yang lebih baik untuk meningkatkan kapasitas infiltrasi dan menyimpan air. Genangan yang terjadi dapat disebabkan kondisi tanah yang dangkal sehingga pada saat hujan turun air tidak dapat langsung mengalir ke drainase, sedangkan kapasitas tanah dan kemampuan vegetasi dalam menyerap air mencapai batas maksimal. Selain itu, Titik 1 dan Titik 2 merupakan area yang dipenuhi dengan aktivitas manusia yang berjualan. Hal ini mengakibatkan tanah semakin padat dan minim rerumputan karena adanya pijakan manusia.

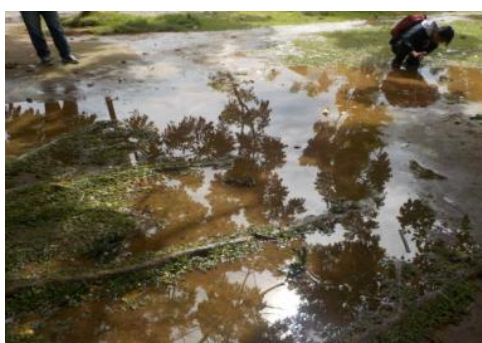

a) Titik 1

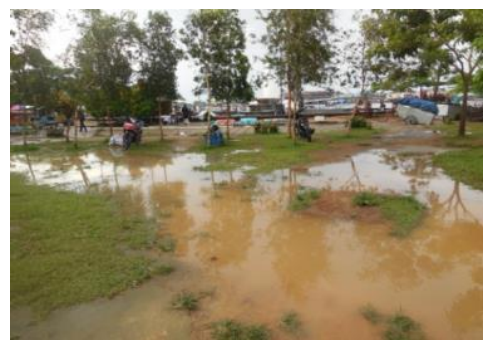

b) Titik 2

Gambar 3. Area Genangan 
Vegetasi pada Titik 3 didominasi dengan perdu dan ground cover. Pada Titik 3 tidak terjadi genangan meskipun tidak mempunyai vegetasi pohon. Hal ini dapat disebabkan air hujan yang turun langsung mengalir ke drainase. Sedangkan, pada Titik 4 mempunyai pohon kelapa dan rerumputan yang rapat dibandingkan dengan titik pengukuran yang lain. Titik 4 merupakan area dengan laju infiltrasi tergolong sangat cepat sehingga tidak terjadi genangan. Kondisi ini dapat disebabkan pada saat terjadi hujan, vegetasi mengurangi pukulan tetesan dan sistem perakaran yang mengakses air dengan cepat sebelum air meresap ke dalam tanah. Hal ini sesuai dengan pendapat Rawls (2003), peningkatan infiltrasi ini disebabkan oleh peningkatan bukaan akar dan perlindungan daun yang melindungi tanah dari pemadatan oleh air hujan.

\section{Potensi Resapan Taman Alun Kapuas}

Pada penelitian ini dilakukan pengukuran luas area dengan menggunakan aplikasi Autocad. Taman Alun Kapuas mempunyai luas sebesar 1,721 ha atau $17.210 \mathrm{~m}^{2}$ dengan persentase penutupan lahan bervegetasi sebesar 22\% dan lahan perkerasan sebesar 78\%. Hasil tersebut menunjukkan bahwa luas area hijau di Taman Alun Kapuas belum memenuhi kriteria taman kota dalam Masterplan Ruang Terbuka Hijau Kota Pontianak dengan RTH 80-90\%. Lahan perkerasan yang ada di Taman Alun Kapuas meliputi paving block, keramik, bangunan, semen dan aspal.

Data curah hujan yang digunakan dalam perhitungan volume resapan adalah curah hujan Kota Pontianak selama 10 tahun dari tahun 2004-2013. Rata-rata curah hujan tahunan diperoleh sebesar $3.184,25 \mathrm{~mm}$. Volume curah hujan dalam satu tahun dikali dengan rata-rata curah hujan tahunan dengan luas area total Taman Alun Kapuas. Koefisien resapan untuk lahan penghijauan dapat diketahui dari volume resapan dalam satu tahun dikali dengan rata-rata laju infiltrasi dan area ruang terbuka hijau di Taman Alun Kapuas, kemudian dibagi dengan volume curah hujan dalam satu tahun dikali dengan rata-rata curah hujan tahunan dengan luas area total Taman Alun Kapuas. Berikut ini adalah perhitungan koefisien resapan untuk lahan penghijauan.

$$
\begin{aligned}
& C H=\frac{P}{1000} \times A \times C=\frac{3.184,25 \mathrm{~mm}}{1000} \times 17.210 \mathrm{~m}^{2}=54.801 \mathrm{~m}^{3} \\
& R=\frac{I \times 365 \times A}{P \times A}=\frac{5,62 \times 24 \times 10^{-2} \times 365 \times 3.800}{3184,25 \times 10^{-3} \times 17.210}=\frac{1.871 .886,71}{54800}=34,16 \approx 34
\end{aligned}
$$

Jika nilai koefisien yang didapat $\geq 1$, maka nilai yang dipakai adalah 1 . Nilai $\geq 1$ menunjukkan laju infiltrasi $\geq$ curah hujan yang ada di daerah tersebut sehingga banyaknya air yang dapat dinfiltrasi adalah $100 \%$ dari volume air hujan total (Nurman, 2014). Koefisien resapan untuk perkerasan berupa paving block, keramik, bangunan, semen dan aspal dapat diketahui dengan persamaan: $\mathrm{R}=1-\mathrm{C}$, dimana koefisien limpasan (C) mengacu pada Suripin (2003). Berikut ini adalah hasil perhitungan volume limpasan dan volume resapan di Taman Alun Kapuas. 
Tabel 3. Volume Limpasan dan Resapan di Taman Alun Kapuas

\begin{tabular}{|c|l|c|c|c|c|c|c|c|}
\hline $\begin{array}{c}\text { Tutupan } \\
\text { Lahan }\end{array}$ & \multicolumn{1}{|c|}{ Jenis } & $\begin{array}{c}\text { Luas } \\
\left.\mathbf{( m}^{\mathbf{2}}\right)\end{array}$ & $\begin{array}{c}\mathbf{\%} \\
\text { Luas }\end{array}$ & $\mathbf{C}$ & $\mathbf{R}$ & $\begin{array}{c}\mathbf{C H} \\
(\mathbf{m m})\end{array}$ & $\begin{array}{c}\text { Volume } \\
\text { Limpasan } \\
\left(\mathbf{m}^{\mathbf{3}}\right)\end{array}$ & $\begin{array}{c}\text { Volume } \\
\text { Resapan } \\
\left(\mathbf{m}^{\mathbf{3}}\right)\end{array}$ \\
\hline \multirow{4}{*}{$\begin{array}{c}\text { Perkerasan } \\
78 \%\end{array}$} & Aspal & 2.073 & 12 & 0,95 & 0,05 & $3.184,25$ & 6.272 & 330 \\
\cline { 2 - 9 } & Keramik & 1.070 & 6 & 0,95 & 0,05 & $3.184,25$ & 3.238 & 170 \\
\cline { 2 - 9 } & Semen & 3.076 & 18 & 0,95 & 0,05 & $3.184,25$ & 9.306 & 490 \\
\cline { 2 - 9 } & Bangunan & 302 & 2 & 0,50 & 0,50 & $3.184,25$ & 481 & 481 \\
\cline { 2 - 9 } & Paving Block & 6.888 & 40 & 0,70 & 0,30 & $3.184,25$ & 15.353 & 6.580 \\
\hline $\begin{array}{c}\text { Penghijauan } \\
22 \%\end{array}$ & $\begin{array}{l}\text { Lahan } \\
\text { Bervegetasi }\end{array}$ & 3.800 & 22 & 0,00 & 1,00 & 3184,25 & 0 & 12.100 \\
\hline \multicolumn{2}{|c|}{ Jumlah } & $\mathbf{1 7 . 2 1 0}$ & $\mathbf{1 0 0}$ & & & & $\mathbf{3 4 . 6 5 0}$ & $\mathbf{2 0 . 1 5 1}$ \\
\hline
\end{tabular}

Sumber: Hasil Analisis, 2015

Berdasarkan pada Tabel 3. dapat diketahui potensi peresapan air hujan dalam satu tahun di Taman Alun Kapuas sebesar $20.151 \mathrm{~m}^{3}$ dari volume total curah hujan sebesar $54.801 \mathrm{~m}^{3}$, maka sejumlah $34.650 \mathrm{~m}^{3}$ air hujan akan menjadi genangan dan terbuang ke saluran drainase. Angka ini menunjukkan bahwa Taman Alun Kapuas belum memenuhi fungsi ekologis sebagai area resapan karena kemampuan menyerap air hujan hanya sebesar $37 \%$. Padahal, daerah taman kota sebaiknya mempunyai daya resap tanah terhadap air hujan sebesar 75 - 95\% (Kusnaedi, 2002)

\section{E. Rekomendasi}

Untuk mengoptimalkan fungsi ekologis Taman Alun Kapuas sebagai area resapan dapat dilakukan berbagai upaya sebagai berikut.

1. Memperluas area penghijauan agar diperoleh volume resapan yang lebih besar.

2. Pemilihan jenis dan komposisi vegetasi yang tepat untuk resapan.Vegetasi pohon yang rimbun dan sistem perakaran yang dalam dapat memperbaiki struktur tanah seperti trembesi, mahoni, akasia, dan kelapa. Vegetasi ground cover juga diperlukan untuk mengurangi pukulan dari tetesan air hujan pada tanah.

3. Mengganti beton atau aspal dengan paving yang berlubang-lubang. Air dapat meresap ke dalam ruang di antara batu paving, sehingga mengurangi jumlah air limpasan

4. Memberikan himbauan kepada masyarakat untuk tidak melakukan kegiatan sosialekonomi pada area penghijauan karena dapat menyebabkan pemadatan. tanah dan vegetasi rumput berkurang.

\section{KESIMPULAN}

Berdasarkan pada uraian di atas dapat disimpulkan beberapa hal sebagai berikut.

1. Laju infiltrasi rata-rata Taman Alun Kapuas pada kondisi hari tidak hujan sebesar 5,62 $\mathrm{cm} / \mathrm{jam}$ lebih besar dari kondisi hari hujan sebesar $3,20 \mathrm{~cm} / \mathrm{jam}$. Hal ini menunjukkan curah hujan dapat menurunkan laju infiltrasi tanah.

2. Laju infiltrasi tertinggi pada Titik 4 sebesar $14,40 \mathrm{~cm} /$ jam dengan tanah pasir sebesar $64,64 \%$, permeabilitas $26,29 \mathrm{~cm} / \mathrm{jam}$, dan porositas $55,42 \%$. Laju infiltrasi terendah pada Titik 3 sebesar 2,02 dengan tanah pasir $54,41 \mathrm{~cm} / \mathrm{jam}$, permeabilitas 5,14 $\mathrm{cm} / \mathrm{jam}$, dan porositas $47,33 \%$. Semakin besar permeabilitas, porositas dan tekstur tanah berfraksi pasir maka laju infiltrasi besar.

3. Kondisi vegetasi pada Titik 1 , Titik 2 , dan Titik 4 didominasi dengan pohon dan rerumputan, sedangkan pada Titik 3 didominasi dengan tanaman groundcover dan 
perdu. Komposisi vegetasi berupa pohon dan rerumputan mempunyai laju infiltrasi lebih besar daripada vegetasi berupa tanaman groundcover dan perdu.

4. Potensi peresapan air hujan dalam satu tahun di Taman Alun Kapuas sebesar $37 \%$ dari volume total curah hujan sebesar $54.801 \mathrm{~m}^{3}$, sehingga belum memenuhi fungsi ekologis taman kota sebagai area resapan sebesar $75-95 \%$.

\section{UCAPAN TERIMAKASIH}

Dengan selesainya penelitian ini saya mengucapkan terima kasih yang sebesarbesarnya kepada Allah Swt, kedua orang tua, kedua dosen pembimbing yaitu Ibu Yulisa Fitrianingsih, S.T, M.T dan Bapak Agus Ruliyansyah, S.P, M.Si serta kepada teman-teman Teknik Lingkungan 2011 dan semua orang yang telah berperan dalam membantu penelitian yang tidak dapat di ucapkan satu persatu. Harapan saya penelitian ini dapat bermanfaat bagi semua dan dapat dipergunakan sebagaimana mestinya.

\section{DAFTAR PUSTAKA}

Andayani, Sejati. 2009. Laju Infiltrasi Tanah pada Tegakan Jati (Tectona grandis linn F) di BKPH Subah KPH Kendal Unit I Jawa Tengah. Institut Pertanian Bogor: Bogor

Arsyad, S. 1989. Konservasi Tanah dan Air. IPB Press: Bogor.

Asdak, C. 2002. Hidrologi dan Pengelolaan Daerah Aliran Sungai. Gadjah Mada University Press: Yogyakarta.

Harto, Sri. 1993. Analisis Hidrologi. Gramedia Pustaka Utama: Jakarta

Hammer, W.I. 1981. Soil Canservation Consultant Report. Indonesia Technical Note: Bogor

Hillel, D. 1971. Soil and Water Physical Principles and Process. Academic Press: New York Kohnke, H. 1980. Soil Physics. McGraw-Hill Book Company: New York.

Kurnia, et al. 2006. Sifat Fisik Tanah dan Metode Analisisnya. Balai Litbang Sumberdaya Lahan Pertanian: Bogor

Kusnaedi. 2002. Sumur Resapan untuk Permukiman Perkotaan dan Perdesaan. Penebar Swadaya: Jakarta

Bappeda, 2012. Masterplan Ruang Terbuka Hijau Kota Pontianak. Bappeda Kota Pontianak: Pontianak

Menteri Pekerjaan Umum. 2008. Pedoman Penyediaan dan Pemanfaatan Ruang Terbuka Hijau di Kawasan Perkotaan. Peraturan Menteri Pekerjaan Umum: Jakarta

Rawls, et al. 2003. Effect of Soil Organic Carbon on Soil Water Retention. Geoderma:USA

Sinukaban, Naik 2007. Konservasi Tanah dan Air: Kunci Pembangunan Berkelanjutan.

Direktorat Jenderal RLPS: Jakarta

Soepardi, G., 1975. Konduktivitas Hidrolik. Penerbit ANDI: Yogyakarta

Soeharto, E. 2006. Kapasitas Simpan Air Tanah pada Sistem Tata Guna Lahan LPP Tahura Raja Lelo. Jurnal Ilmu-ilmu Pertanian Indonesia: Bengkulu

Suripin. 2003. Sistem Drainase Kota yang Berkelanjutan. Penerbit Andi: Yogyakarta

Wirosoedarmo, Ruslan, dkk. 2009. Evaluasi Laju Infiltrasi pada Beberapa Penggunaan Lahan Menggunakan Metode Infiltrasi Horton di Sub Das Coban Rondo. Universitas Brawijaya: Malang 